\title{
Elevator Exhaustion Time Reduction by Eliminating Fake Demands
}

\author{
${ }^{1}$ Qusay Shihab Hamad, ${ }^{2}$ Yasir Hassan Ali, ${ }^{3}$ Falah Y.H. Ahmed, ${ }^{4,5}$ Abdoulhdi. A. Borhana, ${ }^{6}$ Ahmed M. \\ ${ }^{7}$ Abdelrhman, Salah M. Ali, ${ }^{8}$ Hilal A. Fadhil, ${ }^{9}$ Muayad Sadik Croock \\ 1 University of Information Technology and Communications (UOITC)-Baghdad-Iraq, \\ 2 North Technical University (NTU), Technical Collage Mosul, Mosul, Iraq. \\ 3 Department of Information Science and Computing, Faculty of Information Sciences and Engineering (FISE), \\ Management and Science University, 40100 Shah Alam, Selangor, Malaysia \\ 4 Department of Mechanical Engineering, College of Engineering, Universiti Tenaga Nasional, BN - 03-33, Jalan \\ IKRAM-UNITEN, 43000 Kajang, Selangor Darul Ehsan. \\ 5 Department of Mechanical Engineering, College of Engineering Science \& Technology, Sebha University - \\ Sebha, Libya. \\ 6 Department of Mechanical Engineering, School of Engineering, Bahrain Polytechnic, 33349 Isa Town, Kingdom \\ of Bahrain. \\ 7 Institute of Noise and Vibration, Universiti Teknologi Malaysia, Jalan Sultan Yahya Petra, 54100 Kuala Lumpur, \\ Malaysia. \\ 8 Al-Farabi University College- Computer Engineering Dep. 9 Department of Computer Engineering, University of \\ Technology, Baghdad, Iraq. \\ 1 engitq@yahoo.com ORCID ( 0000-0002-8699-2586 ),2 yha2006@ntu.edu.iq
}

\begin{abstract}
. achieving the highest performance and efficiency of elevators have become an important area of research in the world of elevators. Because of the accelerating nature of the world, the interest in time and the rush to accomplish business became a major need for mankind. And that high buildings rely mainly on elevators, reducing the response time of the elevator is the most important research areas, so in this research, we propose an idea to provide the elevator to the person and not to false demand and this requires detection the presence of someone waiting for the elevator to the proposed system provides an algorithm based on the sensor PIR (passive infrared sensor). The results showed the size of profit achieved by the system and the profit is divided into profit times (reduce response time which leads to increase comfort for the rest of the people) and profit in reducing the energy consumed by the elevator.
\end{abstract}

Keywords: Elevator, Time Saving, PIR, Arduino, servo motor

\section{Introduction}

Elevators, as a vertical moving machine for transporting people in the low-to-high rise buildings and towers, play an important role as being a great necessity in human daily city life. This unavoidable dependence on elevators especially in high buildings requires a reliable, availability, and superior riding comfort with efficient management.. [1,2].

the significant issue appears in the last decade was energy saving and how human can efficiently manage the energy sources. so that many researchers in the world worked in these aspects to find efficient ways to manage the limited energy resources. [3, 4, 5].

The usage number of elevators and the growing amount are both the first in the world. Power consumption of the elevators is a serious problem that can take up 17\% 25\% of the total energy consumption 
of high buildings, following directly air-conditioning power consumption. Thus, designing techniques for elevator energy saving are a promising research orientation $[6,7]$.

Therefore, it is important to design a control system for the elevator to reduce power consumption. This paper proposes an elevator control system that aims to minimize power consumption by minimizing the average waiting time for the elevators' passengers by preventing fake requests.

\section{Related Works}

Over the last decennium, many researchers worked on improving the quality of elevators. Improving the energy efficiency and performance of elevators by direct-landing the elevator place control system introduces in [1], the authors of [8] introduce Enhancing an elevator efficiency by using super capacitor. Design of Elevator Control System Based on PLC and Frequency Conversion Technology was presented in [9]. analysis of an elevator energy regeneration unit for saving energy in a building was shown in [10]. the authors of [11] show a model elevator control system based on NI Compact RIO and LabVIEW.

\section{METHODOLOGY}

\subsection{Designed Monitoring Scheme}

In this Section the designed blueprint of the proposed system is introduced. This system contains two control units. main control unit: it is connected with elevator motor, multi small control unit one for each floor. The main objective is controlling the work of the elevator cab based on received messages from the floor control unit.

floor control unit: it is connected with push-button, door motor and two passive infrared sensors (PIR) in each floor install two PIR to detect passenger to insure the elevator cab move to real passenger and prevent fake requests. Many times, a person calls an elevator but when the elevator has moved. He or she decides to leave the elevator and when it arrives at the floor, there is no one waiting for it. So that leads to consuming power and waste of time, time is very important to improve elevator performance. The proposed system tray is to improve performance and provide a comfortable place for people in the building and save power.

When a person calls for an elevator the floor control unit checks the PIR sensor if any sensor detects a person the floor control unit sends a request message to the main control unit. After it has sent the message to the floor control unit wait I second and the check PIR sensor to ensure the person still needs an elevator if it isn't detecting any person by PIR sensor then it sends a message (abort mission) to the main control unit.

To increase the accuracy of detecting passengers by PIR sensor the proposed system makes a change in the building design by making a waiting room in this room the elevator and the PIR Installed in opposite walls as shown in figure number 1 below. 


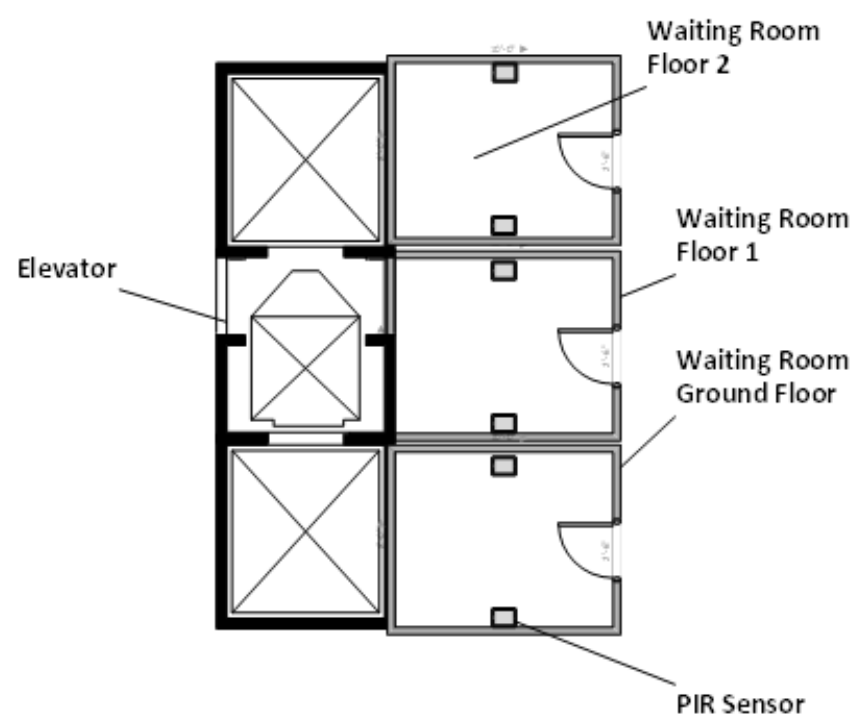

Fig. 1: waiting room show PIR

The system block diagram is shown in figure number 2 below.

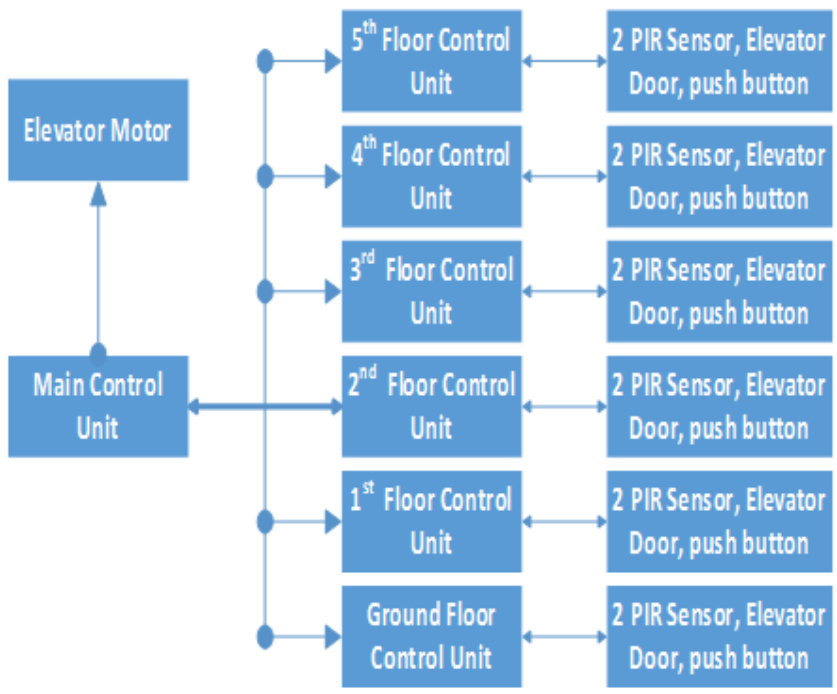

Fig. 2: The system block diagram

\subsection{Algorithm Proposed}

As mentioned, the proposed system includes an algorithm used to control the operations of the elevator. Two types of algorithms used in this system one of them are in the main control unit and the other is in each floor control unit. Figure number 3 shows the main algorithm while figuring the number 4 show subroutine that controls the elevator door. 


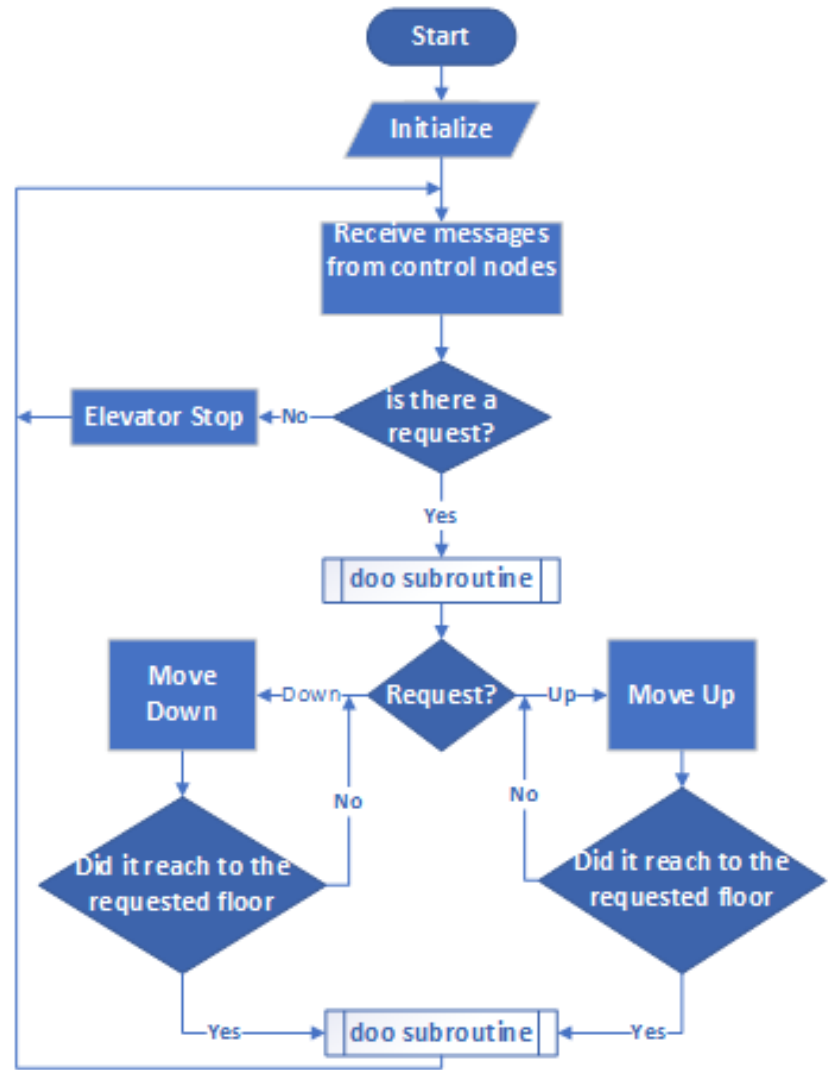

Fig. 3: flow chart of the main control unit

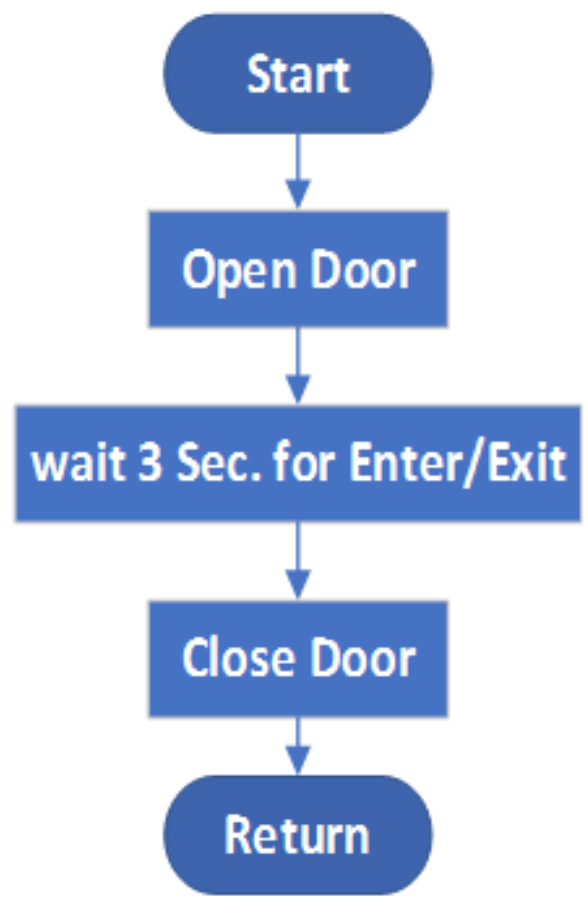


Fig. 4: flow chart of elevator door subroutine

The flow chart of the floor control unit shown in figure number 5 below.

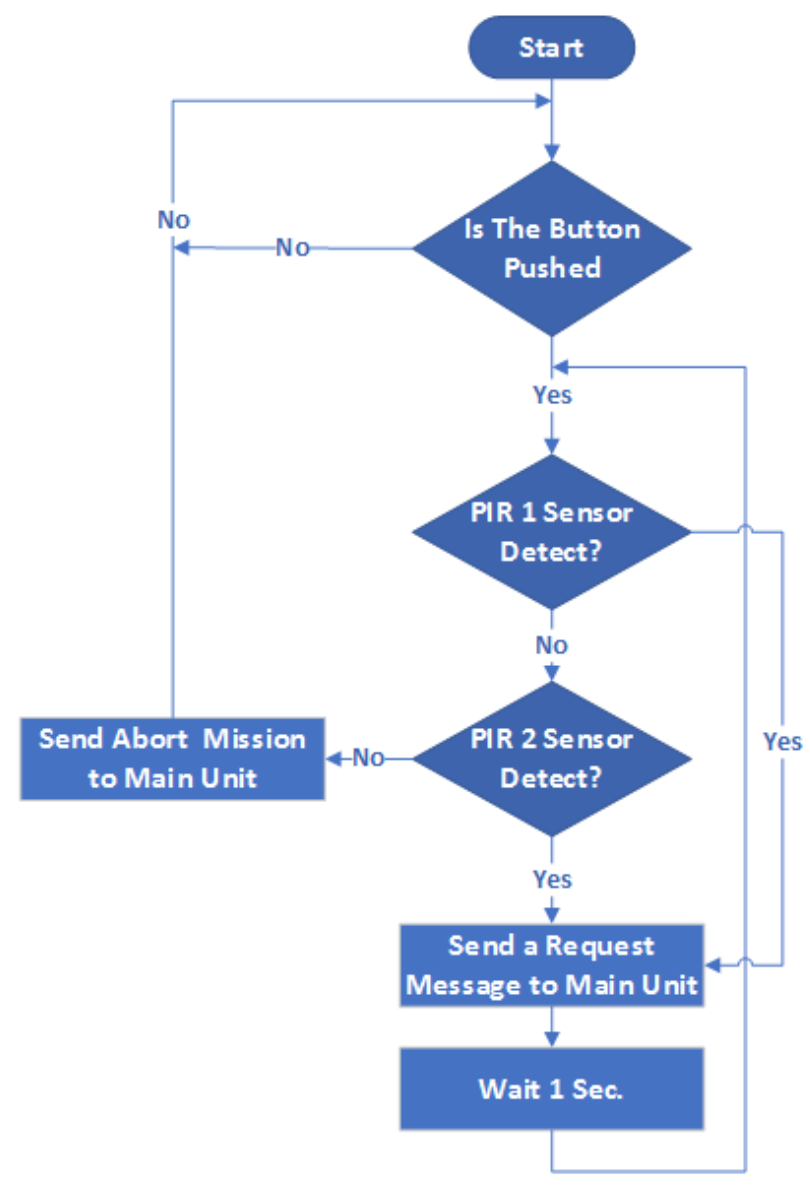

Fig. 5: flow chart in floor control unit

\section{Hardware}

\subsection{Hardware Components}

\subsubsection{Arduino Uno}

It is a microcontroller board based totally at the atmega328p. it has 14 digital enter/output pins (of which 6 may be used as PWM outputs), 6 analog inputs, a $16 \mathrm{MHz}$ quartz crystal, a USB connection, and a reset button; it incorporates everything needed to aid the microcontroller; join it to a laptop with a USB cable or energy it with AC-to-DC adapter or battery to get commenced [8]. Figure number 6 show the Arduino UNO. 


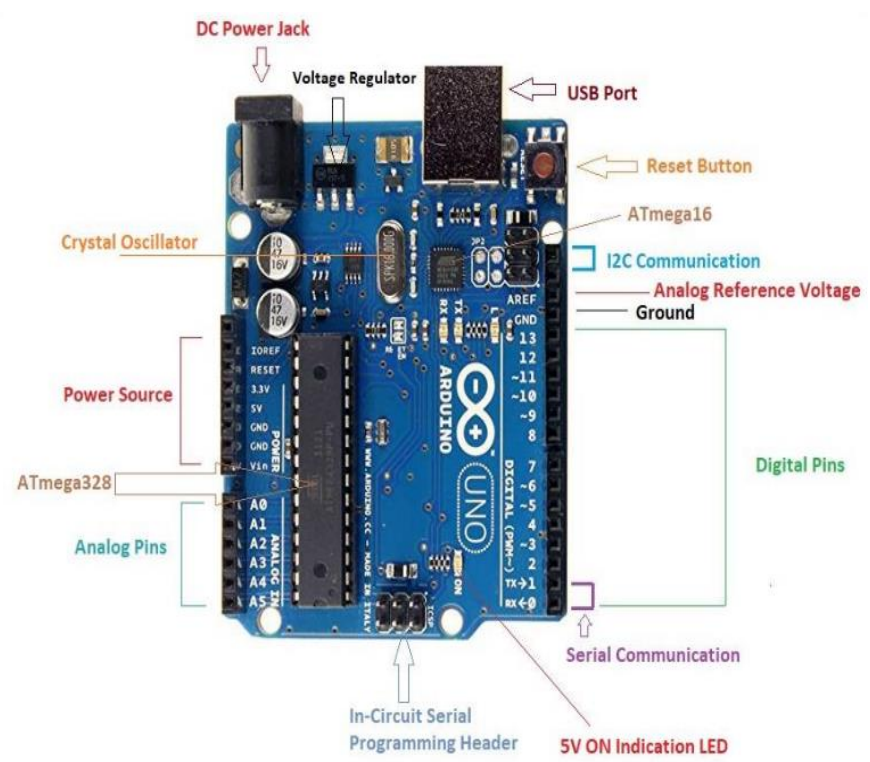

Fig. 6: Arduino UNO

\subsubsection{PIR Sensor}

PIR sensor is broadly used to detect upon the movement of a human. infrared (IR) light is electromagnetic radiation with a wavelength between 0.7 and three hundred micrometers. human beings are the supply of infrared radiation. it changed into observed that the regular human body temperature radiates IR at wavelengths of ten micrometers to twelve micrometers [11]. Figure number 7 show PIR sensor.

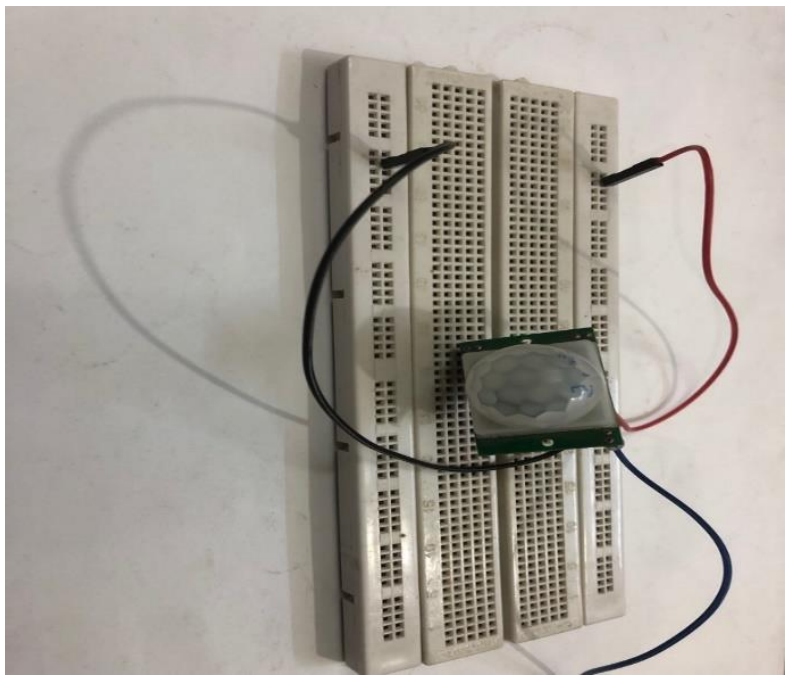

Fig. 7: PIR sensor

\subsubsection{Servo Motor}

a servo motor is a device that contains an encoder which converts the mechanical motion (turns of the shaft) into digital pulses interpreted through a movement controller. it additionally includes a driver; and in conjunction, they make up a circuit that governs the position, torque and velocity [13]. 


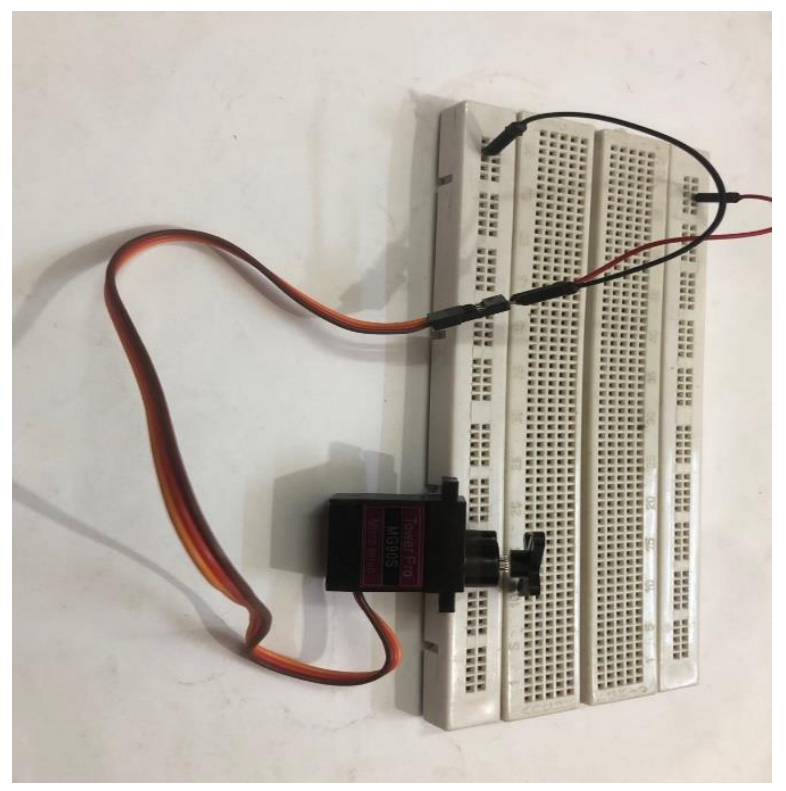

Fig. 8: servo motor

\subsection{Hardware Circuit}

The hardware circuit of the proposed project clarified in figure number 8 shown below.

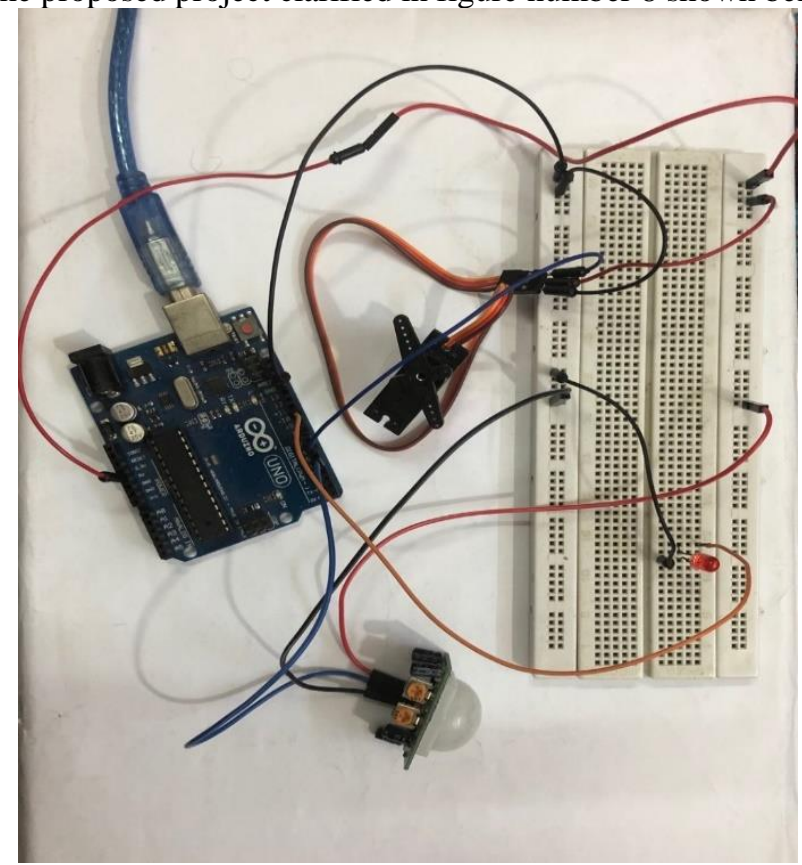

Fig. 9: hardware circuit

In this circuit, we used one PIR sensor instead of two to test the algorithm and used LED as an elevator door. 


\section{Simulation Result}

To show the advantages of the proposed system we present two scenarios. The power consumption for an elevator depends on the passenger-carrying capacity and no. of floors it serves equal 30481200 KWs [15].

\subsection{Scenario one:}

Passenger A on floor 3 calls an elevator (he wants to exit the building) after one-second passenger B on floor 5 calls an elevator. The elevator cab will respond to this order. When the elevator cab reached floor number 2, passenger B remembered something in his apartment so he left the waiting room. In this moment the room control unit on floor 5 sends a message to the main control unit to abort the mission. So when the elevator cab reached the third floor it opened and passenger A got in and went down to the ground floor without going up to the fifth floor. The profit of the proposed system compared with systems available in markets based on time is presented below in table number 1. Figure number 10 shows profit in energy consumption.

Table 1: profit of the proposed system in scenario 1

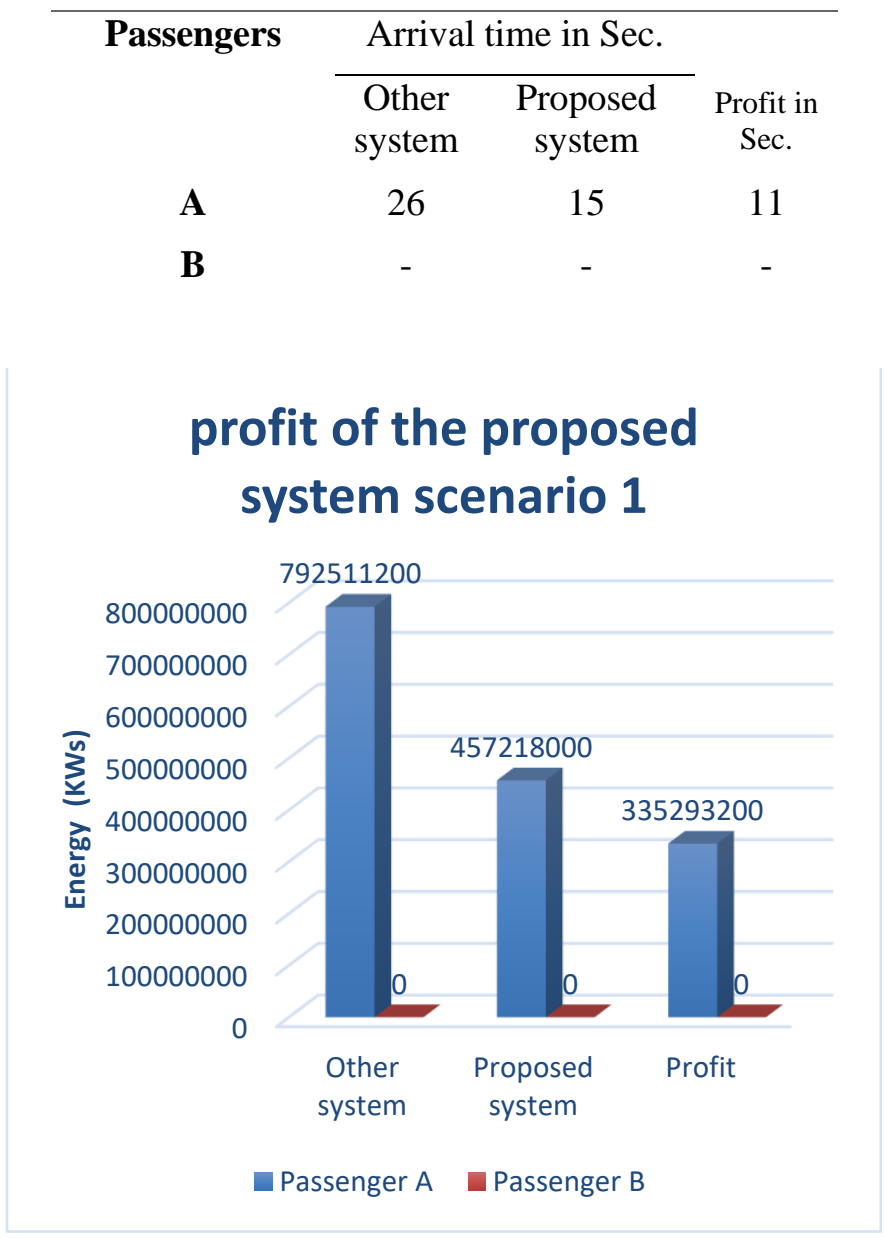

Fig. 10: profit in energy consumption in scenario 1

\subsection{Scenario two:}

Passenger A is on the fifth floor and the elevator cab is on the third floor (idle state) passenger A calls an elevator because he wants to reach to the ground floor. After a moment passenger B arrive at the building and he calls the elevator to take him to his flat on the second floor. When the elevator cab is in midway between 
3rd and 4th floor (after one second) passenger A left the waiting room for some reason at this moment the 5th control unit sends a message to the main control unit so that the elevator cab reverses its direction and descend down towards the ground floor to take passenger B to the second floor. The profit of the proposed system compared with systems available in markets based on time is presented below in table number 2. Figure number 11 shows profit in energy consumption.

Table 2. profit of the proposed system in scenario 2

\begin{tabular}{cccc}
\hline & \multicolumn{3}{c}{ Arrival time in Sec. } \\
Passengers & $\begin{array}{c}\text { Other } \\
\text { system }\end{array}$ & $\begin{array}{c}\text { Proposed } \\
\text { system }\end{array}$ & $\begin{array}{c}\text { Profit } \\
\text { in Sec. }\end{array}$ \\
A & - & - & - \\
B & 24 & 15 & 9 \\
\hline
\end{tabular}

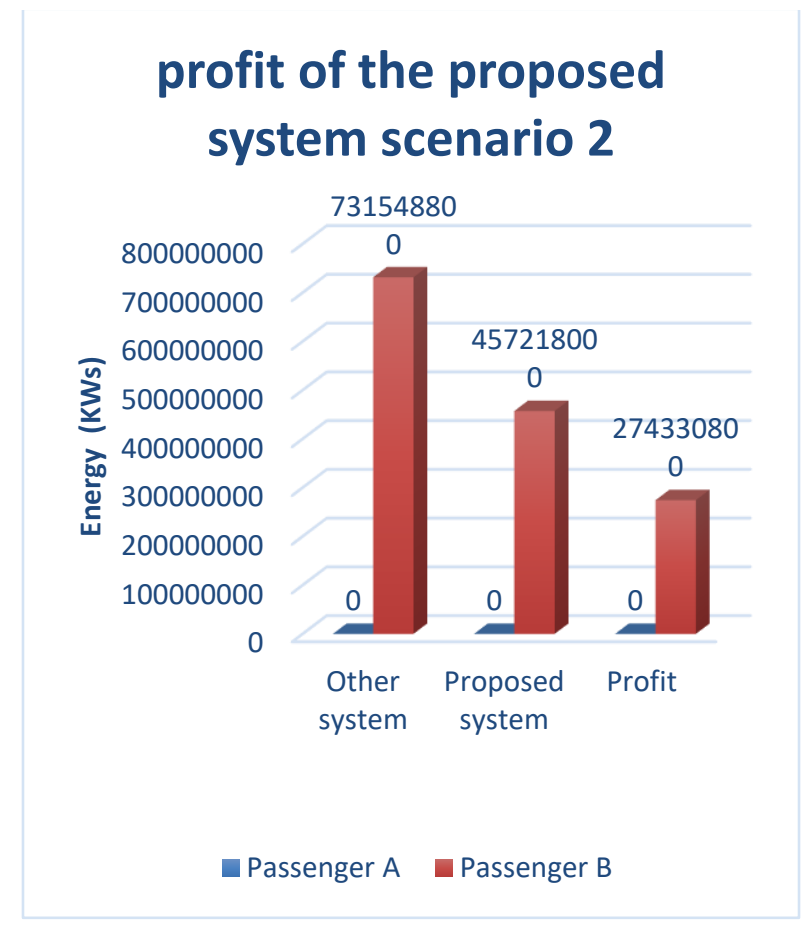

Fig. 11: profit in energy consumption in scenario 2

\section{Conclusions}

In this paper, the new technology was proposed to reduce the time and power consumed in the elevator system available today in the market. The reduction of time leads to providing a comfortable life for the residents of the buildings because they would travel between floors in less time. The system also provides profit to the owners of buildings by reducing energy consumption and elevator maintenance fees in the long term. 


\section{Future work}

the future orientation on expanding the proposed system by adding more than one elevator and controlling them and we develop the algorithm to decide which request must be responded to first and which must wait based on the location of elevator cab or based on the number of passengers to provide a more accurate system and reducing the number of the elevator leading to an expansion in building space that is useful to a solution to the problem of population increase.

\section{References}

[1] E. Ongun and A. Demir, "Improving the Performance and Energy Efficiency of Elevators by Direct-Landing Elevator Position Control System", 4th International Conference on Electrical and Electronics Engineering, IEEE Conferences, 2017.

[2] Q. Hamad and others, "Efficient infrared sensor and camera-based monitoring system", 2013 International Conference on Electrical Communication, Computer, Power, and Control Engineering (ICECCPCE), 17-18 Dec. 2013.

[3] G. Nobile and others, "Energy Harvesting in Roped Elevators", International Symposium on Power Electronics, Electrical Drives, Automation and Motion, IEEE Conferences, 2014

[4] Q. Hamad and others, "Efficient Wireless Sensor Network Based Monitoring System", Adhoc \& Sensor Wireless Networks, Vol. 35 Issue 1/2/2017, pp. 105-128, 2017.

[5] Q. Shihab Hamad, A. Majid Taha, and A. A. Abdulrazzaq, "Company attendance and access control system based on radio frequency identification,” p. 12028, 2019.

[6] L. Hong-peng, L. Kuan, S. Bai-nan, “Analysis of Energy Management Strategy for Energy-Storage Type Elevator Based on Supercapacitor", 11th IEEE International Conference on Compatibility, Power Electronics and Power Engineering (CPEPOWERENG),2017.

[7] Q. Hamad and others, "University attendance and entrance control system using RFID ”, Journal of Engineering and Applied Sciences, Volume: 12 | Issue: 11 SI | Page No.: 9286-9294, 2017.

[8] M. Khamees and others, "Design and implementation of a smart home automation system based on global system for mobile communications", Journal of Applied Engineering Science, Volume 16 article 555 pages: $471-479$, 2018.

[9] P. Kubade and S. Umathe, "Enhancing an elevator efficiency by using supercapacitor”, 3rd International Conference on Advances in Electrical, Electronics, Information, Communication and Bio-Informatics (AEEICB17), IEEE Conferences, 2017.

[10] C. Mingxia, Y. Juncheng and L. Fengming,“ Design of Elevator Control System Based on PLC and Frequency Conversion Technology”, 10th International Conference on Measuring Technology and Mechatronics Automation (ICMTMA), IEEE Conferences, 2018.

[11] S. marsong and B. Plangklang,“ Implementation Analysis of an Elevator Energy Regenerative Unit (EERU) For Energy Saving in a Building”, IEEE Conferences, 2016.

[12] J. Ye and others, "Design of Model Elevator Control System Based on NI CompactRIO and LabVIEW", 9th International Symposium on Computational Intelligence and Design (ISCID), IEEE Conferences, 2016.

[13] M. T. Student, "Passive Infrared ( PIR ) Sensor Based Security System using PSOC," vol. 1, no. December, pp. 804-807, 2014.

[14] "What is a servo motor and when is it used? - CLR Blog," CLR, 2019. [Online]. Available: https://clr.es/blog/en/what-is-servo-motor-and-when-is-it-used/. [Accessed: 8/3/2020].

[15] thyssenkruppelevator, https://www.thyssenkruppelevator.com/tools/energy-calculator/, accessed in 8/3/2020. 